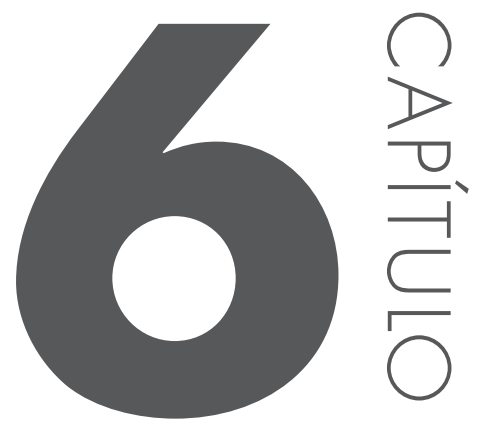

\title{
SUSTENTABILIDADE EMPRESARIAL ATRAVÉS DO GERENCIAMENTO ESTRATÉGICO DOS CUSTOS DE NATUREZA AMBIENTAL
}

Valério Vitor Bonelli (PUCSP)

\section{RESUMO}

Os processos produtivos, principalmente as de transformação, estão cada vez mais voltadas a adequação e às exigências ambientais dos mercados, governos e sociedade, que apesar de demandar um montante financeiro considerável, poderá também trazer benefícios financeiros e vantagens competitivas. Para acompanhar o desempenho da empresa e controlar os custos da qualidade ambiental, cada vez mais a utilização de relatórios gerenciais passa a ser imprescindível. Este trabalho apresenta a necessidade de uso dos relatórios de custos ambientais como ferramenta aos gestores para acompanhamento do comportamento dos custos ambientais, propondo um sistema gerencial de informações ambientais, através da interação ABC/ABM (Activity Based 
Management). O sistema de custos proposto para a apuração dos custos da qualidade ambiental toma por base a contabilidade por atividades ABC (Activity Based Costing), podendo ser vista como uma ferramenta essencial na gestão estratégica de custos, evitando desperdícios e combatendo falhas.

PALAVRAS CHAVE: Custos Ambientais, Gestão Ambiental, Qualidade Ambiental, Melhoria Contínua; Competividade 


\section{INTRODUC̣ÃO}

A Gestão Ambiental consiste de um conjunto de medidas e procedimentos bem definidos e adequadamente aplicados que visam a reduzir e controlar os impactos introduzidos por um empreendimento sobre o Meio Ambiente. O ciclo da Gestão Ambiental, para que haja eficácia, deve cobrir, desde a fase de concepção do projeto até a eliminação efetiva e contínua dos resíduos gerados pelo empreendimento depois de implantado, durante toda sua vida útil, devendo também assegurar a melhoria contínua das condições de segurança, higiene e saúde ocupacional de todos os seus empregados e um relacionamento sadio com os segmentos da sociedade que interagem com esse empreendimento e a empresa. A Gestão Ambiental exige, como premissa básica, um comprometimento da alta direção da empresa e de seus acionistas com o estabelecimento de uma Política Ambiental clara e definida que irá nortear as atividades da organização com relação ao Meio Ambiente assumindo compromisso formal com a sociedade, definindo suas intenções e princípios com relação a seu desempenho ambiental.

A Qualidade é um elemento necessário para que uma empresa seja considerada como competitiva no mercado. A globalização da economia e a conscientização da sociedade estão nos últimos anos forçando as empresas a adotarem uma postura responsável perante o meio ambiente, ou seja, forçando a implantação de um sistema de Gestão Ambiental. A contabilidade tradicional não permite aos gestores obter informações acuradas acêrca dos gastos com o meio ambiente.

O Gerenciamento Ambiental requer a aplicação de um valor considerável de recursos financeiros que precisam ser controlados para que haja uma gestão eficaz dos recursos aplicados no gerenciamento ambiental e conseqüentemente a qualidade ambiental.

A otimização dos custos relacionados ás atividades de natureza ambiental requer ferramentas que possam prever já na fase de concepção de um produto, os resíduos e impactos ambientais que possam haver dentro do seu ciclo de vida, e com um sistema de custos ambientais com relatórios específicos poderá inclusive demonstrar de forma adequada, o nível de exposição da empresa ao risco ambiental.

Informações sobre a atividade econômica de uma empresa e o meio ambiente é uma questão de assumir um compromisso com o desenvolvimento sustentável e com os vários princípios da contabilidade, dentre os quais destacamos o princípio da Continuidade e o da Oportunidade. 


\section{GESTÃO ESTRATÉGICA DOS CUSTOS AMBIENTAIS}

A variável ambiental colabora com a definição de custos, mediante reduções de desperdícios de matérias-primas, energia, multas e custos de remediação decorrentes de uma postura ambiental displicente, principal razão para análise da relação custo/benefício na implantação de um sistema de informações de custos ambientais.

Uma indústria quando decide instalar sistemas que irão proporcionar uma melhoria da qualidade ambiental, como, por exemplo, estações de recuperação de níquel ou de cromo, sistemas de filtragem, há a necessidade de desenvolver ou encomendar projetos, adquirir equipamentos, realizar construções civis (prédios, tubulações etc.), ter a montagem dos equipamentos e o seu funcionamento, com a realização de testes de desempenho. Todas essas atividades geram custos e são analisadas com cuidado, até mesmo porque esses custos ficam bastante visíveis. Entretanto, é preciso lembrar que há uma série de outros custos, que precisarão ser considerados, pois o que interessa é o custo total ligado àquela determinada atividade, ou seja, o custo ao longo do ciclo de vida do produto.

A qualidade ambiental, integrada ao sistema global da organização, pode e deve ser mensurada em termos de custos, embora exista, no início do processo produtivo, dificuldades em se quantificar o que significa realmente qualidade ambiental, embora não seja uma tarefa fácil enquadrar os custos da qualidade ambiental nos sistemas contábeis normais da empresa. A linguagem dos custos, além de ser universal, é aquela mais compreendida pela alta direção, permitindo-lhe realizar as escolhas corretas e visualizar de forma precisa (quantificada) grande parte dos benefícios e lucros decorrentes da implantação dos programas de gestão ambiental.

O maior desafio que as empresas enfrentam na atualidade é conseguir atingir a plenitude no que se refere à qualidade e à produtividade sem incremento em seus custos e, inclusive, objetivando a redução dos mesmos. Tais objetivos são fatores de sobrevivência num mercado cada vez mais exigente e competitivo, requerendo alternativas para superar as dificuldades e facilitar a tomada de decisões. Para que as empresas alcancem suas metas, existe a necessidade da implantação de um processo que analise e gerenciamento dos custos que estrategicamente poderão ser desenvolvidos com pleno sucesso. 


\section{CLASSIFICAC̣ÃO DOS CUSTOS AMBIENTAIS}

A classificação das categorias que compõem o custo da qualidade ambiental, variam muito de indústria para indústria, dependendo de seu desenvolvimento tecnológico com relação a equipamentos que produzam menos resíduos e poluentes, do tipo de produto fabricado, da matéria-prima empregada e principalmente da condição de motivação e treinamento dos funcionários sobre a postura com relação aos problemas ambientais.

Há três tipos de custos ambientais (custos de controle, custos decorrentes da falta de controle e custos contingenciais), compondo situações antagônicas, onde os gastos com controle (prevenção e avaliação) visam diminuir ou eliminar os gastos com falhas internas, externas e contingenciais.

Os custos ambientais são classificados em:

- CUSTOS DE PREVENÇÃO:

- Administração e planejamento da qualidade ambiental

- Treinamento em procedimentos de minimização de rejeitos e efluentes líquidos

- Estudos para implantação da ISO 14001

- Estudos de confiabilidade dos processos quanto a acidentes ambientais

- Elaboração de procedimentos operacionais para operação da ETE

(Estação de Tratamento de Efluente)

- Compra de um novo filtro antipoluente

- Modernização de equipamentos do processo para geração menor de resíduos.

- Gastos com a implantação de sistemas com melhor combustível

- Mão de obra gasta no estudo de modificações do processo produtivo visando a melhorias ambientais

- Análise do projeto de um produto quanto à sua reciclabilidade

- Custos com elaboração do EIA-RIMA (Estudo de Impacto Ambiental

- Relatório de Impacto Ambiental)

- Análise de falhas

- CUSTOS DE AVALIAÇÃO:

- Inspeção de efluentes no processo

- Teste de efluentes em laboratório (composição química)

- Gastos com auditorias ambientais

- Inspeções de rotina nos sistemas industriais de controle de poluição 
- Testes e inspeções de materiais adquiridos quantoà emissão de particulados

- Custos de viagens de inspetores aos fornecedores para avaliar seu

SGA

- Custos dos laboratórios, calibração e reparo de instrumentos usados para medir a composição dos resíduos.

- Laudo de caracterização de resíduos - NBR. 10.004

Custos de falhas internas:

- Retrabalhos em produtos por problemas ambientais

- Perdas de matéria-prima fora dos limites normais

- Desperdícios de energia elétrica e de água

- Gastos com mão-de-obra do pessoal empregado em manuseio de material rejeitado por problemas ambientais

- Remediação de áreas internas contaminadas

- Ações trabalhistas resultantes de condições ambientais inadequadas da empresa

- CUSTOS DE FALHAS EXTERNAS:

- Retrabalho decorrentes de queixas de clientes sobre a qualidade ambiental do produto

- Custos com testes externos para corrigir imperfeições decorrentes de queixas

- Remediações de áreas externas contaminadas

- Recursos legais por problemas ambientais

- Multas de órgãos ambientais

- Remoção (transporte) de resíduos de áreas contaminadas

Custos intangíveis:

- Recall de produtos por problemas ambientais

- Perda de valor da marca em conseqüência de um acidente ambiental

- Excesso de dispêndios na obtenção de licenciamento

- Perda do valor das ações por acidente ambiental

Segundo Bonelli (2002:107) estes gastos poderiam estar apresentados pela figura 1.

Importante seria para a empresa saber quanto custa melhorar e manter a qualidade ambiental desejada, prevista a partir da política ambiental e dos seus objetivos e metas, resposta que precisa ser apoiada por um sistema gerencial de informações da qualidade ambiental. Em suma, o objetivo desse sistema é fornecer dados que permitam, junto com a identificação dos aspectos e impactos ambientais, identificar e tomar ações em áreas 


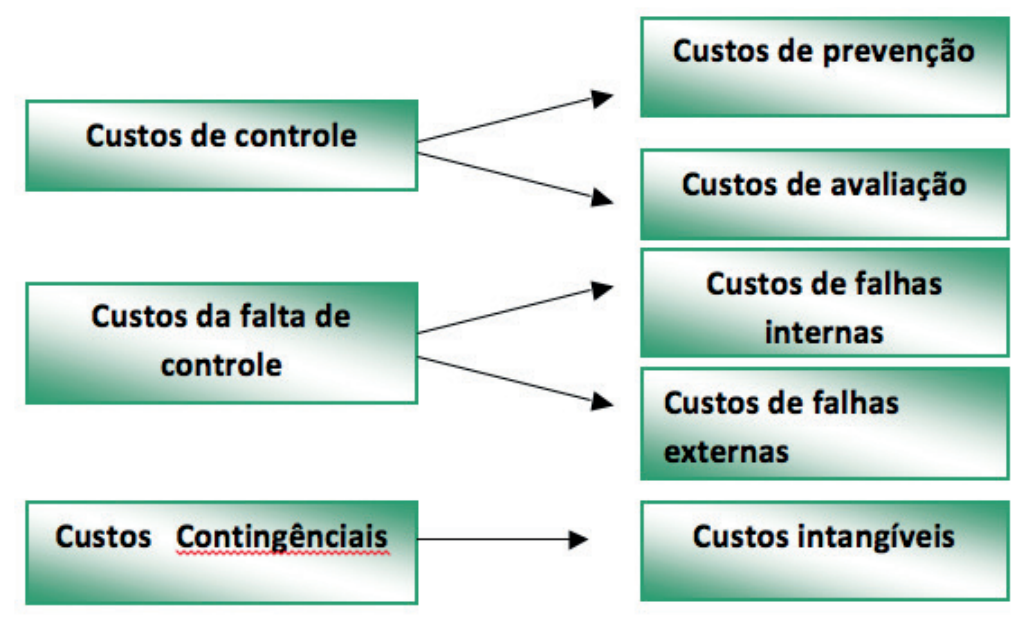

Figura 1 - Identificação dos custos ambientais

Fonte: Bonelli; V.V, Contribuição ao Estudo da Contabilidade Ambiental: Proposta de um modelo de controle gerencial: Dissertação de Mestrado. FECAP/FACESP; 2002.

problemáticas da empresa, de modo a conseguir reduzir os custos totais da qualidade ambiental.

Em uma primeira etapa o que se deseja é que a empresa se situe com seus processos industriais, produtos e serviços dentro de limites aceitáveis principalmente no tocante à produção de poluentes e resíduos, e numa segunda etapa a busca da qualidade ambiental com a política do resíduo/poluição “zero".

\section{GESTÃO AMBIENTAL BASEADA EM ATIVIDADES}

As informações apresentadas quanto ao consumo de recursos pelas atividades de proteção ambiental e pelos produtos possibilitam melhores condições para a determinação de preço e, ainda, para uma real avaliação dos custos/benefícios gerados pela sua manutenção.

A gestão ambiental baseada em atividades (Activity Based Management) consiste em nortear decisões com relação ao meio ambiente de acordo com os relatórios de custos das atividades ambientais.

O sistema proposto por atividades ABC (Activity Based Costing) é uma ferramenta que auxilia os gestores a descobrirem os fluxos do consumo dos recursos da empresa, buscando, na realidade, colocar à sua frente uma informação importante para decisões. Através de análises de atividades conduz ao gerenciamento por atividade ABM (Activity Based Management). 
O ABM utiliza como principal fonte de informação a análise baseada em atividade, ou seja, para se implementar um gerenciamento baseado em atividade é preciso já ter sido implementado o ABC (Activity Based Costing) na empresa. Neste sentido KAPLAN \& COOPER (1998) apud (MIRANDA \& WANDERLEY 2001) apontam que "O ABC levou naturalmente ao gerenciamento baseado em atividade, que se configura como um conjunto de medidas interligadas que só podem ser tomadas com base em informações provenientes de sistemas de custeio baseado na atividade".

A gestão ambiental baseada em atividades deve pressupor a definição dos vários processos gerenciais da função meio ambiente. Essa função teria o mesmo "status" na empresa das demais funções, como Marketing, Finanças, Produção, Recursos Humanos e outras. Essa função poderia ser alocada à logística da empresa ou ficar subordinada diretamente à presidência, constituindo uma diretoria autônoma.

Considerando que o sistema de gestão ambiental consome recursos, ressalta-se a indispensável integração entre o gerenciamento ambiental e a gestão estratégica de custos.

$\mathrm{Na}$ área ambiental, seja na forma preventiva, de controle ou de recuperação, os gastos têm significativo impacto sobre o patrimônio das empresas e, por essa razão, devem ser alvo de criteriosas estratégias, de forma a garantir o sucesso dos sistemas de gerenciamento ambiental adotados pelas companhias e, consequentemente, a continuidade dos negócios destas.

A seguir, apresentamos um exemplo da classificação dos custos da Qualidade Ambiental. A avaliação das parcelas de custos de controle, das falhas de controle e das contingenciais pode ser feita para cada processo (analisando-se os efluentes e resíduos produzidos em cada processo industrial, ou em cada produto, conforme seja possível obter dados de custos), ou para um determinado processo ou produto ao longo do tempo. Esta última forma é mais efetiva para demonstrar as melhorias obtidas ao longo do tempo, permitindo-se julgar a validade ou não da realização do investimento e o desempenho do gerenciamento ambiental. Os relatórios podem permitir conclusões sobre quanto se economizou, como ficaram os custos em relação às vendas e outras análises que orientem o planejamento estratégico da empresa na área ambiental. 
Quadro 1 - Classificação Custos Ambientais. Período jan a dez/2002.

\begin{tabular}{|c|c|c|c|c|c|}
\hline \multirow[t]{2}{*}{ HISTÓRICOS DOS CUSTOS } & \multicolumn{5}{|c|}{ CUSTOS AMBIENTAIS RS } \\
\hline & PREVENĈ̣̃O & AVALIAC̣̃̃o & $\begin{array}{l}\text { FALHAS } \\
\text { INTERNAS }\end{array}$ & $\begin{array}{c}\text { FALHAS } \\
\text { EXTERNAS }\end{array}$ & INTANGIVEIS \\
\hline $\begin{array}{l}\text { TESTE DE EFLUENTES EM LABORATÓRIO } \\
\text { (COMPOSIÇÃO QUUIMICA) }\end{array}$ & & 11.300, & & & \\
\hline GASTOS COM TRANSPORTES DE RESÍDUOS & 11.300, & & & & \\
\hline GASTOS COM AUDITORIA AMBIENTAIS & & 13.200, & & & \\
\hline $\begin{array}{l}\text { TESTES E INSPEC̦̃̃ES DE MATERIAIS ADQUIIIDOS } \\
\text { QUANTO À EMISSÃO DE PARTIICULADOS }\end{array}$ & & 900 & & & \\
\hline $\begin{array}{l}\text { ANÁLISE DO PROJETO DE UM PRODUTO } \\
\text { QUANTO À SUA RECICLAGEM }\end{array}$ & 7.700 & & & & \\
\hline RETRABALHOS EM PRODUTOS POR PROBLEMAS AMBIENTAIS & & & 13.800 & & \\
\hline $\begin{array}{l}\text { CUSTOS DE VIAGENS DE INSPETORES AOS } \\
\text { FORNECEDORES PARA AVALLAR SEU SGA }\end{array}$ & & 5.400 & & & \\
\hline $\begin{array}{l}\text { CUSTO DOS LABORATÓRIOS, CALIBRACÃ̃O E } \\
\text { REPARO DE INSTRUMENTOS USADOS PARA } \\
\text { MEDIR A COMPOSIÇÃ̃O DOS RESÍDUOS }\end{array}$ & & 1750, & & & \\
\hline $\begin{array}{l}\text { CUSTOS COM TESTES EXTERNOS PARA CORRIGIR } \\
\text { IMPERFIC̄ÕES DECORRENTES DE QUEIXAS }\end{array}$ & & & & 15.100, & \\
\hline ESTUDOS PARA IMPLANTAÇ̃̃O0 DA ISO 14001 & 22.300, & & & & \\
\hline CUSTOS COM ELABORAÇÃO DO EIA-RIMA & 32.750 & & & & \\
\hline REMEDIAC̦ÃO DE ÁREAS INTERNAS CONTAMINADAS & & & & 21.400 & \\
\hline $\begin{array}{l}\text { ELABORAC,ÃO DE PROCEDIMENTOS } \\
\text { OPERACIONAIS PARA OPERAC̦ÃO DA ETE }\end{array}$ & 5250 & & & & \\
\hline $\begin{array}{l}\text { AÇ̃OES TRABALHISTAS RESULTANTES DE CONDICT̃̃ES } \\
\text { AMBIENTAIS INADEQUADAS DA EMPRESA }\end{array}$ & & & 9.200 & & \\
\hline $\begin{array}{l}\text { TREINAMENTO EM PROCEDIMENTOS DE } \\
\text { MINIMIZAÇÃ̃O DE REJEITOS }\end{array}$ & 5.180, & & & & \\
\hline COMPRA DE UM NOVO FILTRO & 1.520 & & & & \\
\hline $\begin{array}{l}\text { MODERNIZACÃO DE EQUIPAMENTOS DO } \\
\text { PROCESSO PARA GERAR MENOS RESÍDUOS }\end{array}$ & 15.200, & & & & \\
\hline PERDA DO VALOR DAS AÇ̃̃ES POR ACIDENTE AMBIENTAL & & & & & 20.970 \\
\hline TOTAIS & 101.200, & 32.550, & 23.000, & 36.500 & 20.970, \\
\hline \multicolumn{6}{|l|}{ DISTRIBUICC̃̃O DOS CUSTOS EM PERCENTUAIS } \\
\hline & $\%$ & & & RS & \\
\hline PREVENÇÃOO & 47 & & & 101.200 & \\
\hline AVALLAÇÃO & 15 & & & 32.550, & \\
\hline FALHAS INTERNAS & 10 & & & 23.000 & \\
\hline FALHAS EXTERNAS & 19 & & & 36.500 & \\
\hline INTANGIVEIS & 9 & & & 20.970 & \\
\hline TOTAIS & 100 & & & 214.220, & \\
\hline
\end{tabular}




\section{CUSTOS POR PROCESSOS}

Apresentamos a seguir simulações de custos ambientais por processo.

Quadro 2 - Custos Ambientais Totais por Processo - RS

\begin{tabular}{|c|c|c|c|c|c|}
\hline & $\begin{array}{l}\text { PROCESSO A } \\
\text { FUNDIÇÃO (S) }\end{array}$ & $\begin{array}{l}\text { PROCESSO B } \\
\text { USINAGEM (\$) }\end{array}$ & $\begin{array}{c}\text { PROCESSO C } \\
\text { ACABAMENTO (\$) }\end{array}$ & $\begin{array}{l}\text { PROCESSO D } \\
\text { PINTURA (S) }\end{array}$ & $\begin{array}{l}\text { PROCESSO E } \\
\text { TESTE, MONTAGEM } \\
\text { E EXPEDICC̄ÃO (S) }\end{array}$ \\
\hline PREVENC̣̃̃O & 5.230 & 6.460 & 7.800 & 8.270 & 1.200 \\
\hline AVALIAĈ̣̃̃O & 4.700 & 5.330 & 4.020 & 6.220 & 940 \\
\hline $\begin{array}{l}\text { FALHAS } \\
\text { INTERNAS }\end{array}$ & 3.250 & 5.100 & 1.800 & 930 & 1.400 \\
\hline $\begin{array}{l}\text { FALHAS } \\
\text { EXTERNAS }\end{array}$ & 2.230 & 2.700 & 800 & 840 & 1.250 \\
\hline INTANGÍVEIS & 905 & 0 & 0 & 1.900 & 5.790 \\
\hline TOTAL RS & 16.315 & 19.590 & 14.420 & 18.160 & 10.580 \\
\hline INVESTIMENTO & 0 & 1.000 & 5.000 & 0 & 0 \\
\hline RED. CUSTO & 0 & 0 & $26 \%$ & 0 & 0 \\
\hline
\end{tabular}

O Processo B é aquele no qual ocorrem os maiores dispêndios em termos de custo global, porém o Processo "E”, apesar de possuir menores dispêndios, possui uma concentração maior em custos de falhas externas e nos custos intangíveis. Nesse exemplo, os Processos "D" e "E” necessitam de maior atenção por parte dos gestores, pois comprometem a performance ambiental.

\section{UTILIDADE DOS RELATÓRIOS DE CUSTOS AMBIENTAIS}

Estrategicamente, a principal meta de um sistema de custos ambientais é facilitar os esforços de melhoria da gestão ambiental, através do gerenciamento por atividades que terão como objetivos a criação de oportunidades de redução de custos.

Segundo Robles Junior (2003:101) as premissas estratégicas para a utilização plena do sistema de custos da qualidade, que também poderiam ser definidas na gestão do meio ambiente, são:

a) para cada falha, sempre haverá uma causa; 
b) as causas são evitáveis;

c) a prevenção sempre é mais barata.

Com base nessas premissas, são recomendadas as seguintes estratégias na utilização do sistema de custos ambientais:

1. Atacar diretamente os custos das falhas, para inverter sua tendência. Como meta deve-se buscar a eliminação dos custos das falhas.

2. Os investimentos devem ser direcionados para a prevenção correta, ou seja, aquela que propiciará maiores melhorias.

3. De acordo com os resultados alcançados em (1) e (2), as atividades de avaliação devem ser descontinuadas, conseqüentemente, haverá redução nos custos de avaliação.

4. A avaliação contínua dessa sistemática propiciará a oportunidade de se redirecionarem os esforços com prevenção para obter, mais para frente, outras melhorias.

Analisando a eficácia do modelo apresentamos a seguir um exemplo do retorno sobre o investimento em Qualidade Ambiental ( ROIQA), através do gerenciamento por atividades $(\mathrm{ABM})$ temos :

Quadro 3 - Roiqa Através do Gerenciamento por Atividades

\begin{tabular}{|c|c|c|c|c|}
\hline \multicolumn{5}{|c|}{ EVOLUC̣̃̃O DE VÁRIOS PERÍODOS } \\
\hline CATEGORIA DO CUSTO AMBIENTAL & 2003 (R\$) & 2004 (R\$) & 2005 (R\$) & 2006 (R\$) \\
\hline PREVENÇÃOO & 0 & 5.000 & 4.000 & 2.500 \\
\hline AVALLAC̦ÃO & 0 & 2.000 & 1.000 & 1.000 \\
\hline FALHA INTERNA & 1.000 & 500 & 200 & 100 \\
\hline FALHA EXTERNA & 3.000 & 1.500 & 1.000 & 500 \\
\hline CONTINGENCIAIS & 5.000 & 3.000 & 1.000 & 500 \\
\hline TOTAL DA CATEGORIA & 8.000 & 12.000 & 7.200 & 4.600 \\
\hline CUSTO TOTAL DE FABRICAC̦ÃO (CTF) & 32.000 & 32.000 & 32.000 & 32.000 \\
\hline INVESTIMENTO & 0 & 7.000 & 12000 & 15.500 \\
\hline $\begin{array}{l}\text { CUSTO TOTAL AMBIENTAL \% } \\
\text { (TOTAL DA CATEGORIA /CTF) }\end{array}$ & $25 \%$ & $37,5 \%$ & $22,5 \%$ & $14 \%$ \\
\hline REDUÇÃO CUSTOS & 0 & 0 & $(800)$ & $(3400)$ \\
\hline $\begin{array}{l}\text { ROIQA (RETORNO SOBRE INVESTIMENTO } \\
\text { EM QUALIDADE AMBIENTAL) }\end{array}$ & 0 & 0 & $6 \%$ & $22 \%$ \\
\hline
\end{tabular}


O quadro anterior demonstra que os gastos efetuados em prevenção podem resultar em mais do que contrabalancear as reduções de custo nas outras categorias. É possível manter ou melhorar a performance ambiental e, ao mesmo tempo, reduzir drasticamente os custos totais ambientais.

O impacto de investimentos no segmento superior de prevenção pode produzir benefícios ao longo de diversos anos, mas há uma defasagem de tempo entre os gastos em prevenção e o resultante decréscimo nos custos das falhas. O quadro acima demonstra que houve um incremento em custos de prevenção e avaliação no ano de 2000, não havendo redução imediata nos custos das categorias inferiores. As reduções de custos totais ambientais bem como o retorno sobre investimento na qualidade ambiental (ROIQA), somente começaram a aparecer em 2001 e 2002.

\section{7. ÍNDICES / INDICADORES DE DESEMPENHO DA GESTÃO AMBIENTAL}

SANTO \& HSIEH (1999) apud BONELLI (2002:128), afirmam existir várias combinações possíveis para a criação de indicadores que podem ser usados para descrever o desempenho ambiental. Para fins deste trabalho, podemos citar os seguintes índices:

- indicador financeiro relacionado com outro indicador financeiro, como por exemplo, passivo ambiental/patrimônio líquido;

- indicador financeiro relacionado com indicador ecológico, como, por exemplo, emissão de CO 2/unidade de produto produzido; e indicador ecológico relacionado com outro indicador ecológico, como por exemplo, resíduo produzido/recurso utilizado;

- quota de reciclagem = proporção de material reciclado por ano/total de material consumido anualmente;

- custo de energia = custo com energia/custos totais de produção;

- quota de resíduos líquidos = quantidade total de efluentes líquidos/custo de controle e recuperação dos efluentes líquidos;

- lucratividade ambiental = receita ambiental/faturamento.

A contabilidade ambiental deve ter objetivos transparentes para toda a empresa. Devem ser gerados relatórios por responsabilidade, a fim de incentivar cada responsável pelos diferentes processos a agir ecologicamente.

O gestor ambiental que estiver bem estruturado com informações de indicadores de desempenho, possui melhores chances de construir estratégias e enfrentar os desafios com responsabilidade social. 


\section{RELATÓRIOS DE SUSTENTABILIDADE}

A sustentabilidade é entendida pelo atendimento do equilíbrio nas complexas relações atuais entre necessidades econômicas, ambientais e sociais que não comprometa o desenvolvimento futuro. Esse entendimento é do GRI, sigla do Global Reporting Initiative, que é um processo internacional de longo prazo, com participação ativa de múltiplas partes interessadas (stakeholders), cuja missão é desenvolver e divulgar as diretrizes para a elaboração de relatórios de sustentabilidade.

\section{Quadro n .4 - Hierarquia das diretrizes}

\begin{tabular}{|c|c|c|}
\hline DIMENSÃO & CATEGORIA & ASPECTO \\
\hline ECONÔMICA & IMPACTOS ECONÔMICOS DIRETOS & $\begin{array}{l}\text { CLLENTES } \\
\text { FORNECEDORES } \\
\text { FUNCIONÁRIOS } \\
\text { INVESTIDORES } \\
\text { ETOR PÚBLIICO }\end{array}$ \\
\hline AMBIENTAL & IMPACTOS AMBIENTAIS & 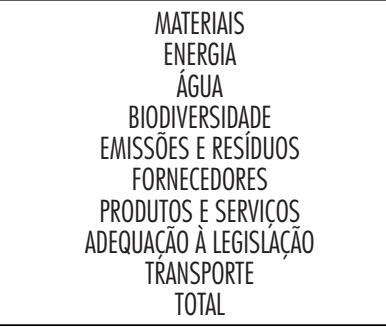 \\
\hline \multirow{4}{*}{ SOCIAL } & PRÁIICAS TRABALHISTAS & $\begin{array}{l}\text { EMPREGO } \\
\text { RELACCOEES COM FUNCIONÁRIOS } \\
\text { SAÚDE E SEGURANCA } \\
\text { TREINAMENTO E EDUCÁCÁCO } \\
\text { DIVERSIDADE E OPORTUNIDADE }\end{array}$ \\
\hline & DIREITOS HUMANOS & 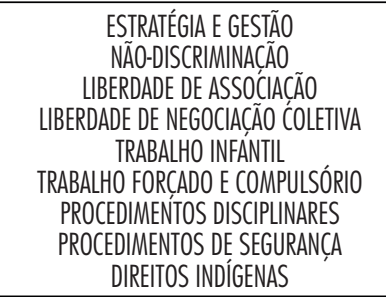 \\
\hline & SOCIEDADE & $\begin{array}{c}\text { COMUNIDADE } \\
\text { SUBORNO E CORRUPCÃO } \\
\text { CONTRIBUICÕES POLIIIICAS } \\
\text { COMPETIĊ̃̃O E POLLITIICAS DE PREÇOS }\end{array}$ \\
\hline & $\begin{array}{l}\text { RESPONSABILIDADE SOBRE } \\
\text { PRODUTOS E SERVICYOS }\end{array}$ & $\begin{array}{c}\text { SAÚDE E SEGURANCA DOS CONSUMIDORES } \\
\text { PRODUTOS E SERVICOS } \\
\text { PROPAGANDA } \\
\text { RESPEITO À PRIVACIDADE }\end{array}$ \\
\hline
\end{tabular}

Fonte: GRI - Diretrizes para relatórios de sustentabilidade - 2002. 
Os relatórios devem abranger as dimensões: econômica, ambiental e social, de acordo com a hierarquia proposta pelo GRI e demonstrada no quadro $n^{\circ}$. 4. Os aspectos apontados nos quadros são mensurados por intermédio de indicadores, que podem ser quantitativos ou qualitativos. Os quantitativos, de acordo com o GRI podem ser ambíguos, daí a necessidade de serem complementados por informações qualitativas na forma de texto. Desta forma a leitura dos relatórios pode proporcionar uma visão mais abrangente do desempenho sustentável, tendo em vista a inter-relação das dimensões econômicas, ambientais e sociais. O GRI enfatiza a necessidade de transformar os indicadores qualitativos em uma escala para facilitar comparações entre diferentes organizações.

A dimensão econômica procura avaliar os impactos econômicos diretos dos fluxos monetários entre a empresa e seus clientes, fornecedores, funcionários, investidores e os governos: municipal, estadual e federal.A GRI subtende que os aspectos financeiros já estão suficientemente desenvolvidos e que são cobertos pelos demonstrativos contábeis e complementados pela análise financeira e notas explicativas tradicionais de praxe.

Os indicadores são considerados essenciais quando são relevantes para a maioria das organizações e importantes para a maioria das partes interessadas. Os indicadores adicionais devem pelo menos atender uma das características: ser relevante e importante para uma determinada e específica categoria de empresas e stakeholders; fornece informações para parceiros e, é candidato a se tornar um indicador essencial no futuro próximo. O GRI flexibiliza a utilização dos indicadores nos relatórios das diretorias, porém reserva-se a certificar se o relatório observa as diretrizes em sua totalidade ou somente em alguns aspectos. A intenção é induzir o uso das diretrizes com o passar do tempo ou por solicitações das partes interessadas (stakeholders).

Os relatórios de sustentabilidade diferenciam-se dos financeiros na amplitude de abrangência. Os financeiros estão voltados principalmente para a gestão interna, os de sustentabilidade visam avaliar os impactos no entorno das áreas de atuação da empresa em termos econômicos, ambientais e sociais. Atualmente, tendo em vista a atuação da empresa, o entorno passa a ser um conceito amplo, visto que as atividades empresariais além de locais, podem, também assumir um caráter regional, nacional e internacional, em outras palavras, a empresa pode atuar em nível global.

Os relatórios de sustentabilidade estão baseados em princípios norteadores. O primeiro é o da transparência, cujo propósito é assegurar a completa divulgação dos processos, procedimentos e hipóteses usados 
na elaboração do relatório. Esse princípio tem por finalidade conferir credibilidade aos propósitos de divulgação dessas informações.

O princípio da inclusão visa engajar as partes interessadas para aumentar a qualidade dos relatórios. O princípio da verificabilidade visa assegurar a rastreabilidade inversa às informações, de tal modo que os auditores externos possam auditar e confirmar os eventos relatados.

$\mathrm{O}$ da abrangência tem por finalidade assegurar que toda a informação de desempenho econômico, ambiental e social é colocada de forma consistente com os limites declarados, o escopo e o prazo. A definição de limites constitui um dos grandes desafios do GRI, visto que a atuação da empresa pode ser em nível global, como exposto anteriormente.

O princípio da relevância sempre foi uma das preocupações dos relatórios financeiros tradicionais. Essa preocupação permanece para os relatórios de sustentabilidade, visto que relevância significa importância $\mathrm{da}$ informação para a entidade relatora e para as partes interessadas. $\mathrm{O}$ princípio chamado: contexto de sustentabilidade significa que a empresa deve situar seu desempenho, se for o caso, além dos seus limites ecológicos e sociais, desde que tal contextualização seja considerada relevante.

O princípio da exatidão refere-se à intenção da empresa atingir um alto grau de exatidão em suas informações, procurando minimizar a margem de erro, a fim de que as partes interessadas possam decidir baseadas em plena confiança.

A neutralidade visa eliminar distorções na seleção e apresentação das informações, procurando apresentar um relato equilibrado do desempenho da organização. Os princípios da comparabilidade, clareza e periodicidade são semelhantes aos dos relatórios financeiros e visam proporcionar aos seus usuários a possibilidade de comparar informações históricas da própria empresa, bem como em relação a outras entidades concorrentes ou não. A clareza está voltada ao atendimento das necessidades das diferentes partes interessadas e pretende atender a maioria dos usuários. Por fim, esses relatórios devem fazer parte da rotina empresarial e precisam ser emitidos e disponibilizados de forma regular e tempestiva, de preferência no site da Internet da empresa.

A figura $\mathrm{n}^{\circ} .1$ demonstra de forma esquemática e hierarquizada os princípios norteadores dos relatórios de sustentabilidade dentro da concepção do GRI. Esses princípios são básicos no processo decisório sobre quais informações incluir, sobre a qualidade e confiabilidade dessas informações, bem como em relação à acessibilidade da informação transmitida, principalmente em relação ao "como" e "quando" essas 
informações foram obtidas; dada à relevância atribuída ao relatado, tendo em vista seus impactos em termos econômicos, ambientais e sociais.

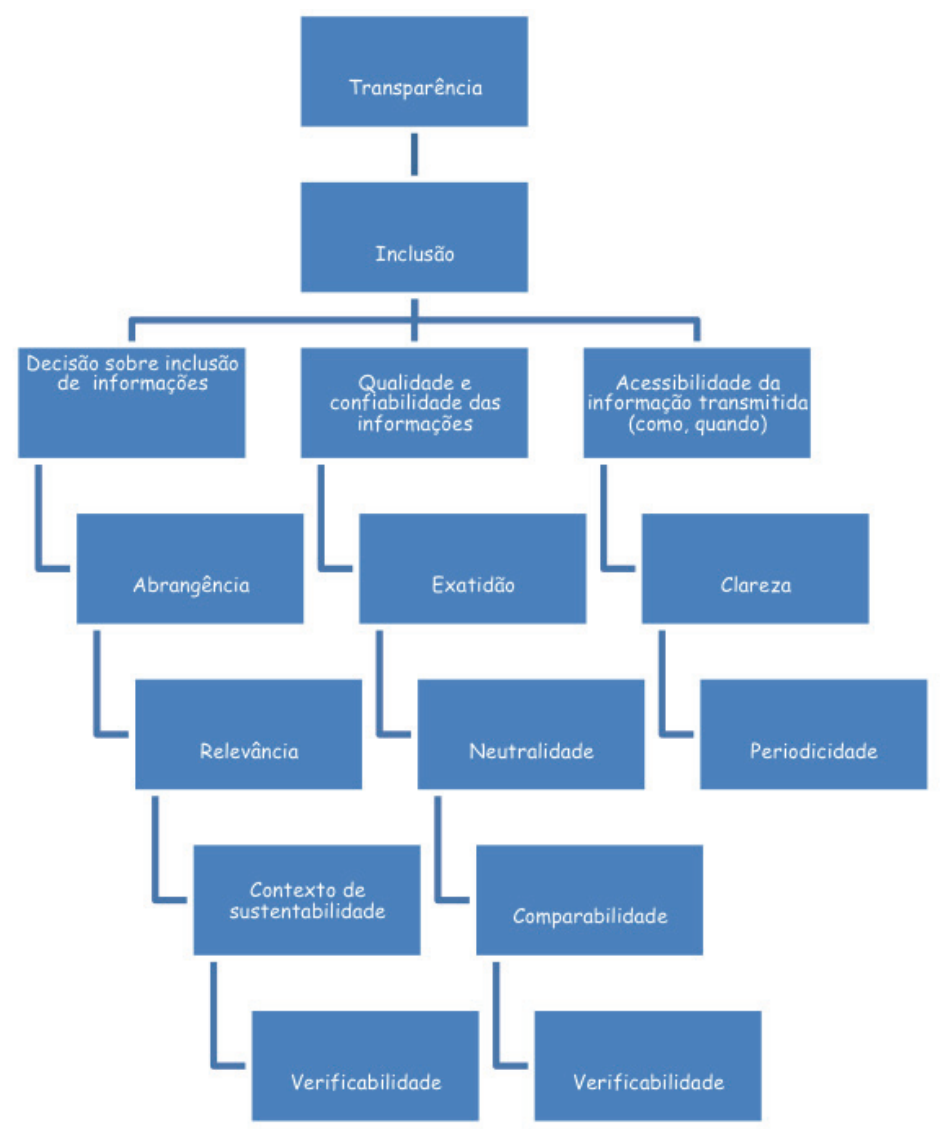

Figura $\mathrm{n}^{0} \mathrm{l}$ - Princípios norteadores dos relatórios de sustentabilidade.

Fonte: Adaptado do GRI - Diretrizes para relatórios de sustentabilidade

Para permitir a captação das informações sobre sustentabilidade a empresa que tiver uma Contabilidade de Gestão Ambiental, conforme proposto neste trabalho, terá mais condições de quitar essa obrigação com seus stakeholders, partes interessadas ou usuários, praticando o Princípio da Accountability, de forma condizente com seus propósitos de prestação de contas com as partes interessadas. 
Com relação às tendências sobre a abrangência das informações, com base no trabalho desenvolvido pelo GRI (Global Reporting Initiative), com o objetivo de divulgar relatórios de sustentabilidade, dentro dos padrões globais, que abrangem, além do desempenho financeiro, os indicadores econômicos, ambientais e sociais. De acordo com as diretrizes desta instituição, o conteúdo dos relatórios seria estruturado como ilustrado na figura a seguir:

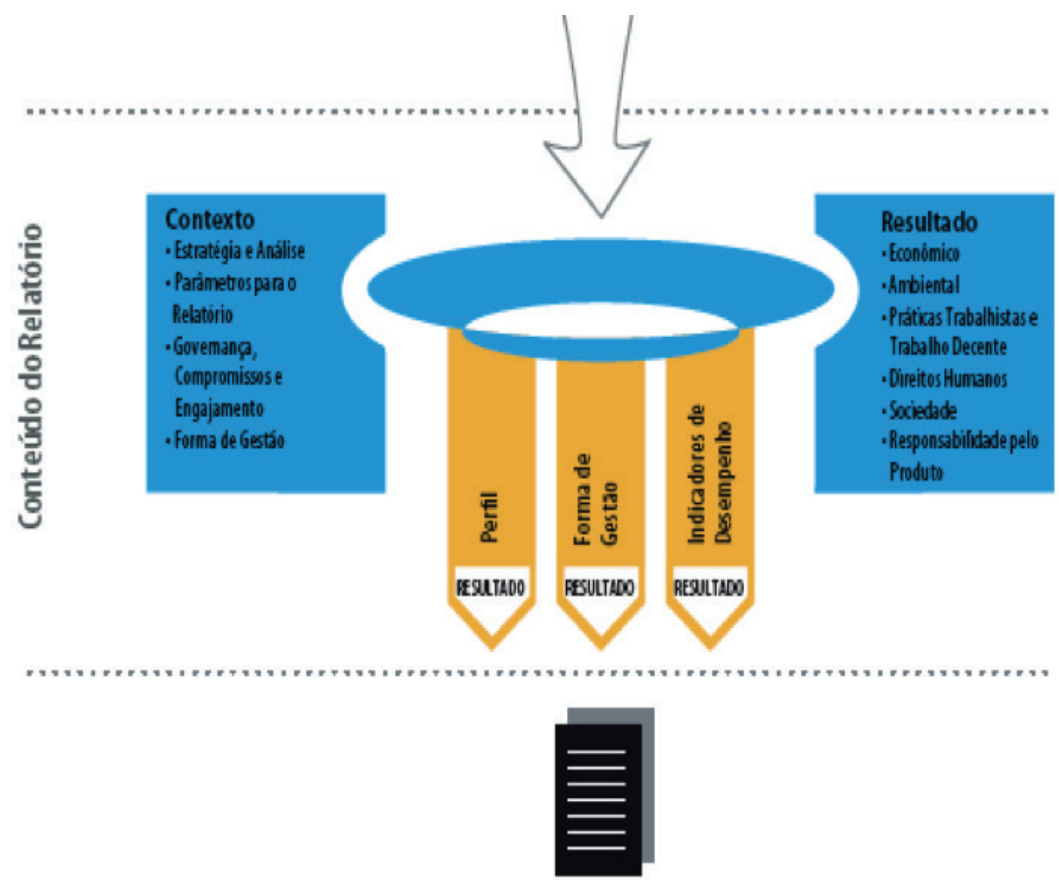

Relatório de Sustentabilidade com Foco

Figura nº 2 - Visão Geral do Conteúdo do Relatório da RGI

Fonte: http://www.globalreporting.org

O quadro a seguir apresenta alguns dos indicadores considerados nos relatórios GRI e que dado aos requisitos de comparabilidade e atualização periódica poderiam ser extraídos de um banco de dados do tipo data warehousing: 


\section{Quadro $n^{\circ} 5$ - Indicadores relevantes estabelecidos pelo GRI que poderiam ser extraídos por meio de data warehousing}

VALOR ECONÔMICO DIRETO GERADO E DISTRIBUIIDO, INCLUINDO RECEITAS, CUSTOS OPERACIONAIS, REMUNERACÃO DE EMPREGADOS,

DOAÇ̄ẼE, OUTROS INVESTIMENTOS NA COMUNIDADE, LUCROS E PAGAMENTOS PARA PROVEDORES DE CAPITAL É GOVERNOS.

IMPLICAÇ̃̃ES FINANCEIRAS E OUTROS RISCOS E OPORTUNIDADES PARA AS ATIVIDADES DA ORGANIZAÇ̃̃O DEVIDO A MUDANÇAS CLIMÁTICAS.

COBERTURA DAS OBRIGAÇ̃̃ES DO PLANO DE PENSÃO DE BENEFícIO DEFINIDO QUE A ORGANIZAÇÃO OFERECE.

AJUDA FINANCEIRA SIGNIFICATIVA RECEBIDA DO GOVERNO.

VARIAC̦̃̃O DA PROPORÇÃO DO SALÁRIO MAIS BAIXO COMPARADO AO SALÁRIO MÍNIMO LOCAL EM UNIDADES OPERACIONAIS IMPORTANTES.

MATERIAIS USADOS POR PESO OU VOLUME.

PERCENTUAL DOS MATERIAIS USADOS PROVENIENTES DE RECICLAGEM.

CONSUMO DE ENERGIA DIRETA E INDIRETA DISCRIMINADO POR FONTE DE ENERGIA PRIMÁRIA.

ENERGIA ECONOMIZADA DEVIDO A MELHORIAS EM CONSERVAC̦Ã̃ E EFICIÊNCIA.

TOTAL DE RETIRADA DE ÁGUA POR FONTE E PERCENTUAL E VOLUME TOTAL dE ÁGUA RECICLADA E REUTLIIZADA.

LOCALIZACÃO E TAMANHO DA ÁREA POSSUÍDA, ARRENDADA OU ADMINISTRADA DENTRO DE ÁREAS PROTEGIDAS, OU

ADJACENTES A ELAS, E ÁREAS DE ALTO ÍNDICE DE BIODIVERSIDADE FORA DAS ÁREAS PROTEGIDAS.

TOTAL DE EMISSÕES DIRETAS E INDIRETAS DE GASES DE EFEITO ESTUFA, POR PESO.

EMISSÕES DE SUBSTÂNCIAS DESTRUIDORAS DA CAMADA DE OZÔNIO, POR PESO.

DESCARTE TOTAL DE ÁGUA, POR QUALIDADE E DESTINAÇÃO.

PESO TOTAL DE RESÍDUOS, POR TIPO E MÉTODO DE DISPOSIÇÃO.

NÚMERO E VOLUME TOTAL DE DERRAMAMENTOS SIGNIFICATIVOS.

PERCENTUAL dE PRODUTOS E SUAS EMBaLAGENS RECUPERAdAS EM RELAÇÃOO AO TOTAL dE PRODUTOS VENDIDOS, POR CATEGORIA dE PRODUTO.

TOTAL DE INVESTIMENTOS E GASTOS EM PROTEÇ̃̃O AMBIENTAL, POR TIPO.

TAXA DE ROTATIVIDADE DE EMPREGADOS, POR FAIXA ETÁRIA, GÊNERO E REGIÃO.

TAXAS DE LESÕES, DOENÇAS OCUPACIONAIS, DIAS PERDIDOS, ABSENTEISMMO E ÓBITOS RELACIONADOS AO TRABALHO, POR REGIĨO.

MÉDIA DE HORAS DE TREINAMENTO POR ANO, POR FUNCIONÁRIO, DISCRIMINADAS POR CATEGORIA FUNCIONAL.

PERCENTUAL DE EMPREGADOS QUE RECEBEM REGULARMENTE ANÁLLSES DE DESEMPENHO E DE DESENVOLVIMENTO DE CARREIRA.

PERCENTUAL DE EMPRESAS CONTRATADAS E FORNECEDORES CRÍTICOS QUE FORAM SUBMETIDOS

A AVALLAÇOES REFERENTES A DIREITOS HUMANOS E AS MEDIDAS TOMADAS.

PERCENTUAL E NÚMERO TOTAL DE UNIDADES DE NEGÓCIOS SUBMETIDAS A AVALIAÇ̃̃̃ES DE RISCOS RELACIONADOS À CORRUPC̦ÃO.

PERCENTUAL DE EMPREGADOS TREINADOS NAS POLĹTICAS E PROCEDIMENTOS ANTICORRUPÇÃO DA ORGANIZAÇÃO.

VALOR MONETÁRIO DE MULTAS SIGNIFICATIVAS E TOTAL DE SANCÕES NÃO MONETÁRIAS

RESULTANTES DA NÃO CONFORMIDADE COM LEIS E REGULAMENTOS.

Fonte: Adaptado de GRI (Global Reporting Initiative), <http://www.globalreporting.org> 


\section{CONCLUSÕES}

O custeamento das atividades de natureza ambiental de forma mais precisa e acurada poderá resultar em redução de custos uma vez que aliada a uma eficiente Gestão Ambiental elimina perdas e aumenta resultados na medida em que melhorias constantes são implementadas para correção de falhas na utilização de recursos.

Os custos relativos ao meio ambiente fazem parte integrante do processo decisório inserido na qualidade total. Portanto, levantamento desses custos torna-se viável através dos conceitos e procedimentos da contabilidade por atividades (ABC), tendo também como ferramenta o ABM (Activity Based Management).

Os relatórios e gráficos de um sistema gerencial de informações ambientais facilitam o relacionamento entre os elementos do custo do meio ambiente fornecendo subsídios e facilitando a tomada de decisões de investimentos nas diferentes categorias que afetam os custos ambientais, com a utilização da ferramenta ABM (Activity Based Management).

O modelo proposto permite aos gestores identificar e eliminar os desperdícios, conduzindo os gestores à melhoria contínua, permitindo ações que venham diminuir o impacto negativo da empresa sobre o meio ambiente. Também confirma o progresso obtido em evitando-se os desperdícios das atividades operacionais e das atividades de natureza ambiental, incluindo neste modelo, os custos intangíveis segregados das demais categorias de custos.

A transparência dos dados ambientais através do uso da ferramenta $\mathrm{ABC} /$ $\mathrm{ABM}$ pode ser usada para diversas finalidades que atendem tanto aos interesses dos empresários quanto da continuidade dos negócios, e de forma indireta constitui instrumento de prestação de contas à sociedade. Essa prestação de contas deve servir para diversas finalidades, tais como: demonstrar a capacitação gerencial da empresa na administração de questões ambientais, mostrando a inserção dessas questões em sua estratégia geral de longo prazo: comparar o progresso entre empresas e durante o decorrer do tempo; e demonstrar de forma adequada, o nível de exposição da empresa ao risco ambiental, e revelar de forma implícita o nível de exposição ao risco ambiental, de tal modo que uma auditoria ambiental pudesse avaliar um determinado nível (alto, médio ou baixo) de exposição ao risco ambiental.

Vale lembrar que somente a mensuração e as informações sobre os Custos da Qualidade Ambiental não resolverão os problemas ambientais e, também, não melhorarão a qualidade ambiental. Porém, tais informações servirão para conscientizar a alta administração das empresas que podem gerar ações para 
propiciar melhorias da qualidade ambiental, subsidiando a decisões a serem tomadas e garantindo a continuidade dos negócios.

A partir da mensuração da qualidade pelos seus custos possibilita o atendimento de alguns objetivos, tais como: (I) identificar a perda da empresa com a falta de qualidade, (II) fixar os objetivos e os recursos para treinamento do pessoal, (III) facilitar a elaboração do orçamento de custos da qualidade, (IV) aumentar a produtividade por meio da qualidade, dentre outros.

Assim, as informações relativas aos Custos da Qualidade Ambiental podem ser utilizadas, de forma indireta, como instrumentos de prestação de contas à sociedade no sentido de demonstrar a capacidade gerencial da empresa na administração das questões ambientais, tornar evidente a inserção da referida questão no planejamento de longo prazo, demonstrar, também, de forma adequada, o nível de exposição de riscos ambientais da empresa e, ainda, possibilitar a verificação do progresso da empresa no processo de melhoria de qualidade ambiental (BONELLI, 2003:149) in Robles (2003). 


\section{REFERÊNCIAS}

BEUREN, I.M.S.V. Custos do ciclo de vida do produto: uma abordagem teórica com ênfase na obtenção de vantagem competitiva. Revista Brasileira de Contabilidade. São Paulo n 106, Jul../Ago.1997.

BOISVERT, H. Contabilidade por Atividades: Contabilidade de Gestão/Práticas avançadas. Traduc̦ão Antonio Diomário de Queiroz. São Paulo: Atlas, 1999.

BONELLI, V.V..Contribuição ao Estudo da Contabilidade Ambiental: Proposta de um modelo de controle gerencial. Dissertacão de Mestrado.FECAP/FACESP, São Paulo, 2002

BONELLI, V.V, ROBLES JUNIOR, A. "ABC/ABM como ferramenta à Gestão Ambiental". Anais do IX Congresso Brasileiro de Custos - 13 a 15/10 - São Paulo/SP, 2002.

BONELL, V.V., ROBLES JUNIOR, A. Gestão do meio ambiente monitorada pela contabilidade baseada em atividades. Anais do VIII Congresso Brasileiro de Custos - 03 a 05/10- São Leopoldo/RS, 2001.

BONELLI, V.V., ROBLES JUNIOR, A . OLIVEIRA A. S. Protocolo de quioto: Viabilidade econômica e sustentabilidade dos projetos de créditos de carbono: Revista eletrônica eGesta, Universidade Católica de Santos: v2 N4, out/dez/2006, p51-72

CHEHEBE, J.R.B. Análise do ciclo de vida de produtos - ferramenta gerencial da ISO 14.000. Rio de Janeiro, Qualitymark. Editora, 1998.

GRI - Global Reporting Initiative, Diretrizes para Relatórios de Sustentabilidade - 2002, Holanda, 2004.

GRI - Global Reporting Initiative, Diretrizes para relatório de sustentabilidade. Disponível em: <www. globalreporting.org>, Acesso em: 13/12/2006. São Paulo, 2006.

KINLAW, D.C. Empresa competitiva ecológica - estratégias e ferramentas para uma administraç̦ão consciente, responsável e lucrativa, trad. Lenke Peres Alves de Araújo. São Paulo: Makron Books, 1997.

MIRANDA, L.C., WANDERLEY, C. Um estudo comparativo entre o Activity Based Management - ABM, o sistema de informação econômica gecon. Anais, do VII Congresso do Instituto Internacional de Custos, Leon/ Espanha, 2001.

MOURA, L.A . A., Economia ambiental - gestão de custos e investimentos. São Paulo: Editora Juarez de Oliveira, 2000.

ROBLES JUNIOR, A. Custos da qualidade: Aspectos Econômicos da gestão da qualidade e da gestão ambiental. São Paulo: 2a. Ed. Atlas, 2003.

ROBLES JUNIOR, A., BONELLI, V.V. Apuraccão dos custos da qualidade e dos custos ambientais através da contabilidade baseada em atividades. Campinas, ENANPAD/2001.

ROBLES JUNIOR, A., BONELLI, V.V Gestão da qualidade e do meio ambiente: enfoque econômico, financeiro e patrimonial. São Paulo: Ed. Atlas, 2006

ROBLES JUNIOR, A., BONELLl, V.V Mensuração dos custos da qualidade ambiental: Estudo de caso da empresa Sipcam Agro S.A. III Congreso de costos Del mercosur 28 y 29 de, agosto : Uruguay, 2007

SANTO, A.E, HSIEH.C. Vantagens competitivas em custos - um enfoque para as questões ambientais. Anais do VI Congresso Brasileiro de custos - São Paulo, 1999. 
